\title{
Copernicus Climate Change Service (C3S) Global Satellite Observations of Atmospheric Carbon Dioxide and Methane
}

\author{
Michael Buchwitz ${ }^{1} \cdot$ Maximilian Reuter ${ }^{1}$. Oliver Schneising ${ }^{1} \cdot$ Heinrich Bovensmann ${ }^{1} \cdot$ John P. Burrows $^{1}$. \\ Hartmut Boesch ${ }^{2}$. Jasdeep Anand ${ }^{2}$. Robert Parker ${ }^{2}$. Rob G. Detmers ${ }^{3}$. Ilse Aben ${ }^{3}$. Otto P. Hasekamp ${ }^{3}$. \\ Cyril Crevoisier $^{4} \cdot$ Raymond Armante $^{4} \cdot$ Claus Zehner $^{5} \cdot$ Dinand Schepers $^{6}$
}

Received: 22 June 2018 / Revised: 5 July 2018 / Accepted: 23 July 2018 / Published online: 24 August 2018

(c) The Author(s) 2018

\begin{abstract}
Carbon dioxide $\left(\mathrm{CO}_{2}\right)$ and methane $\left(\mathrm{CH}_{4}\right)$ are important atmospheric greenhouse gases (GHG) and, therefore, classified as essential climate variables (ECVs). Previously, satellite-derived atmospheric $\mathrm{CO}_{2}$ and methane $\mathrm{CH}_{4} \mathrm{ECV}$ data sets have been generated and made available via the GHG-CCI project of the European Space Agency's (ESA) Climate Change Initiative (CCI, http://www.esa-ghg-cci.org/). The latest GHG-CCI data set, Climate Research Data Package No. 4 (CRDP 4), covers the time period 2003-2015 and is available since February 2017. Currently, the production and provision of these data sets is being continued (pre-)operationally via the Copernicus Climate Change Service (C3S, https://climate.copernic us.eu/), which is implemented by the European Centre for Medium-Range Weather Forecasts (ECMWF) on behalf of the European Commission. The C3S satellite GHG sub-project (C3S_312a_Lot6) is led by University of Bremen supported by University of Leicester (UK), SRON (The Netherlands) and CNRS-LMD (France). The first Climate Data Record (CDR) data set produced and delivered within the $\mathrm{C} 3 \mathrm{~S}$ framework covers the time period 2003-2016 and consists of column-average dryair mole fraction $\mathrm{CO}_{2}$ and $\mathrm{CH}_{4}$ products, i.e., $\mathrm{XCO}_{2}$ and $\mathrm{XCH}_{4}$, from SCIAMACHY/ENVISAT and TANSO-FTS/GOSAT. Furthermore, mid-tropospheric $\mathrm{CO}_{2}$ and $\mathrm{CH}_{4}$ mixing ratios from IASI Metop-A and Metop-B are part of this data set. It is planned to extend this data set each year by one additional year. The data products are available via the Climate Data Store (CDS) of C3S. Here a short overview about this new Earth Observation data set is presented.
\end{abstract}

Keywords Climate change $\cdot$ Essential climate variables $\cdot$ Greenhouse gases $\cdot$ Satellite $\cdot$ Carbon dioxide $\cdot$ Methane

Michael Buchwitz

buchwitz@uni-bremen.de

1 Institute of Environmental Physics (IUP), University of Bremen, Otto Hahn Allee 1, 28334 Bremen, Germany

2 Earth Observation Science, University of Leicester, and NERC National Centre for Earth Observation, Leicester, UK

3 SRON Netherlands Institute for Space Research, Utrecht, The Netherlands

4 Centre National de la Recherche Scientifique (CNRS), Laboratoire de Météorologie Dynamique (LMD), Palaiseau, France

5 European Space Agency (ESA), ESRIN, Frascati, Italy

6 European Centre for Medium-Range Weather Forecasts (ECMWF), Reading, UK

\section{Introduction}

Increasing concentrations of atmospheric carbon dioxide $\left(\mathrm{CO}_{2}\right)$ result in global warming with adverse consequences such as global sea level rise [1]. Despite its importance, our knowledge concerning the various natural and anthropogenic sources and sinks of this greenhouse gas (GHG) has significant gaps. Global satellite observations of $\mathrm{CO}_{2}$ in combination with (inverse) modelling helps to obtain a better understanding of the $\mathrm{CO}_{2}$ sources and sinks (e.g., [2] and references given therein). This requires satellite observations, which are sensitive to $\mathrm{CO}_{2}$ concentration changes close to the Earth's surface as can be obtained from radiance measurements in the short-wave-infrared (SWIR) spectral range, which permit to retrieve column-average dry-air mole fractions of $\mathrm{CO}_{2}$, denoted $\mathrm{XCO}_{2}$, shown in Fig. 1.

Figure 1 shows global maps of $\mathrm{XCO}_{2}$ for selected months in the time period beginning of 2003 to end of 2016 as gener- 


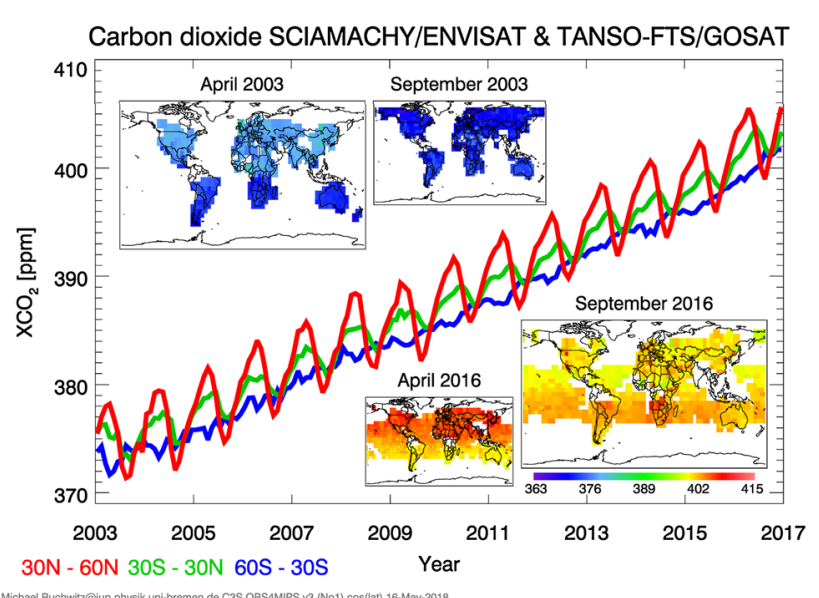

Fig. 1 Time series and global maps of satellite observations of atmospheric carbon dioxide (colour figure online)

ated for the Copernicus Climate Change Service (C3S) and available via the $\mathrm{C} 3 \mathrm{~S}$ website [3]. Also shown are $\mathrm{XCO}_{2}$ time series for three latitude bands: northern mid-latitudes (red), tropics (green) and southern mid-latitudes (blue). As can be seen, all time series show an increasing trend primarily due to burning of fossil fuels. As can also be seen, $\mathrm{CO}_{2}$ varies significantly within each year (especially over the northern hemisphere) due to quasi-regular seasonal uptake and release of atmospheric $\mathrm{CO}_{2}$ by the terrestrial biosphere (photosynthesis, respiration, decay of organic matter). Fortunately, land and ocean sinks currently take up about half of the emitted $\mathrm{CO}_{2}$ [4]. Without these natural sinks the atmospheric increase would be approximately twice as high. However, our knowledge about these important natural $\mathrm{CO}_{2}$ sinks is currently not appropriate for reliable climate prediction as we currently do not know well enough how these natural sinks will respond to a changing climate [1]. Satellite observations such as the ones shown in Fig. 1 are used to obtain a better understanding of the $\mathrm{CO}_{2}$ sources and sinks (e.g., [2] and references given therein).

Atmospheric methane $\left(\mathrm{CH}_{4}\right)$ is also an important greenhouse gas with many natural and anthropogenic sources [1]. Satellite radiance measurements in the SWIR spectral region are also sensitive to near-surface $\mathrm{CH}_{4}$ concentration variations and therefore permit to retrieve column-average dry-air mole fractions of $\mathrm{CH}_{4}$, denoted $\mathrm{XCH}_{4}$, shown in Fig. 2. Atmospheric methane increased by about $150 \%$ since pre-industrial times, but concentrations were nearly constant since the late 1990s. However, since $2007 \mathrm{CH}_{4}$ concentrations started to increase again (Fig. 2). The identification of the reason for this is currently undergoing scientific research (e.g., $[5,6]$ and references given therein).

In the following, a short overview about this new data set is presented.

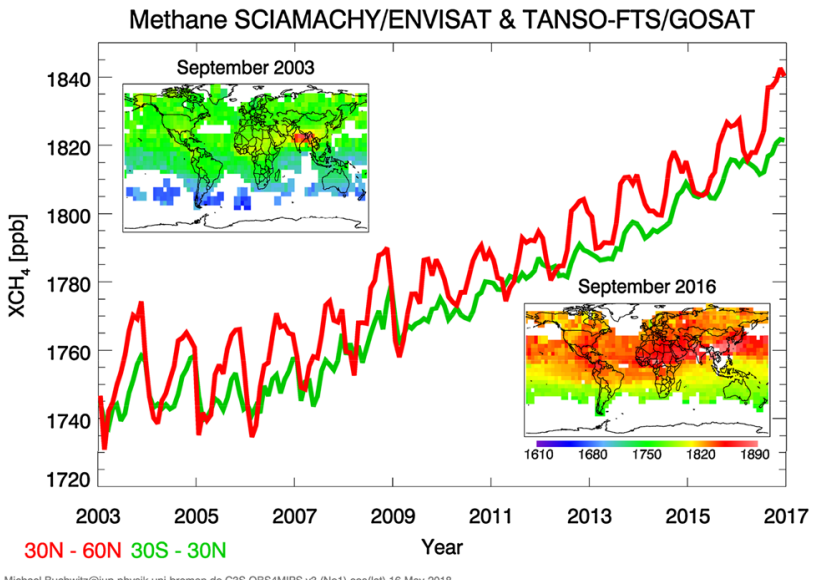

Fig. 2 Time series and global maps of satellite observations of atmospheric methane

\section{C3S Satellite-Derived $\mathrm{CO}_{2}$ and $\mathrm{CH}_{4}$ Data Set}

\subsection{Overview}

The C3S satellite-derived $\mathrm{CO}_{2}$ and $\mathrm{CH}_{4}$ data set has been generated by applying dedicated retrieval algorithms (e.g., [2, 7] and references given therein) to the satellite radiance measurements in order to obtain individual satellite-sensor Level 2 data products, which provide atmospheric $\mathrm{CO}_{2}$ and/or $\mathrm{CH}_{4}$ information for individual satellite footprints (ground pixel). These data products contain for each satellite footprint in addition to information on $\mathrm{CO}_{2}$ and $\mathrm{CH}_{4}$ (and corresponding uncertainty estimates) also a number of other important quantities such as exact location and time of each observation, used a priori information (e.g., a priori profiles) and information on the altitude sensitivity of the retrievals (averaging kernels) [7].

As described in more detail below, these fundamental individual-sensor Level 2 data products are (depending on product type) merged to generate higher-level data products ("merged Level 2" and "merged Level 3" products).

The current $\mathrm{C} 3 \mathrm{~S} \mathrm{CO}_{2}$ and $\mathrm{CH}_{4}$ data set has been generated using these satellite instruments (see $[2,7]$ and references given therein):

- SCIAMACHY on ENVISAT (2002-2012) and TANSOFTS/GOSAT (since mid 2009) for the $\mathrm{XCO}_{2}$ and $\mathrm{XCH}_{4}$ data products (see Figs. 1, 2)

- IASI on Metop-A and Metop-B for $\mathrm{CO}_{2}$ and $\mathrm{CH}_{4}$ midtropospheric mixing ratios and AIRS for mid-tropospheric $\mathrm{CO}_{2}$.

The current (and first) C3S data set covers the years 2003-2016. It is planned to add each year one additional year. This may include re-processing of entire individual-sensor 
time series if improved retrieval algorithms are available; the merged products will always be based on re-processing for each new data set. The next data set will cover the time period 2003-2017 and will be available end of 2018 including documentation (updated user guide, algorithm descriptions, initial data quality documentation, etc.).

\subsection{Requirements}

Requirements for satellite-derived essential climate variable (ECV) data products have been formulate by Global Climate Observing System (GCOS) [9] and these requirements have been considered for the generation of the data products described here and for the corresponding User Requirements Document (URD) of the GHG-CCI pre-cursor project (available from [10]) and for the corresponding C3S Target Requirements Document (TRD) (available from [3]).

The most challenging requirement is the accuracy or bias requirement for $\mathrm{XCO}_{2}$, where a relative accuracy of better than $0.5 \mathrm{ppm}$ (approx. 0.1\%) is required. The reason for this demanding requirement is that even very small errors can result in large regional-scale $\mathrm{CO}_{2}$ surface flux errors depending on the spatio-temporal structure of the $\mathrm{XCO}_{2}$ biases.

\subsection{Data Products}

The $\mathrm{C} 3 \mathrm{~S}$ satellite-derived $\mathrm{CO}_{2}$ and $\mathrm{CH}_{4}$ data set consists of three types of data products (see [7] for details):

1. Individual-sensor Level 2 (L2) products: $\mathrm{XCO}_{2}, \mathrm{XCH}_{4}$ and mid-tropospheric $\mathrm{CO}_{2}$ and $\mathrm{CH}_{4}$ information for individual footprints of individual satellites as generated using dedicated retrieval algorithms

2. Merged L2 products: a single $\mathrm{XCO}_{2}$ and a single $\mathrm{XCH}_{4}$ product covering the entire time period (currently 2003-2016) generated by merging individual sensor L2 products [including GOSAT products from National Aeronautics and Space Administration (NASA) and Japan's National Institute for Environmental Studies (NIES)] using the Ensemble Median Algorithm (EMMA) [11]

3. Merged Level 3 (L3) products: gridded monthly $\mathrm{XCO}_{2}$ and $\mathrm{XCH}_{4}$ products (at $5^{\circ} \times 5^{\circ}$ spatial resolution) in Obs4MIPs format (see [7]) as generated from the merged L2 products (see Figs. 1, 2).

The products are listed in Table 1. Each individual product has a product ID indicating if it is a $\mathrm{CO}_{2}$ or $\mathrm{CH}_{4}$ product, the corresponding satellite ( $\mathrm{SCI}=\mathrm{SCIAMACHY}, \mathrm{GOS}=$ GOSAT, IASA/IASB $=$ IASI Metop-A or $\mathrm{B}, \mathrm{AIR}=\mathrm{AIRS}$ ) and the used retrieval algorithm.
Table 1 List of data products

\begin{tabular}{lll}
\hline Type & Quantity & Product ID \\
\hline L2 & $\mathrm{XCO}_{2}$ & CO2_SCI_BESD \\
& & CO2_SCI_WFMD \\
& & CO2_GOS_OCFP \\
& & CO2_GOS_SRFP \\
L2 & Mid-tropospheric & CO2_IASA_NLIS \\
& $\mathrm{CO}_{2}$ & CO2_IASB_NLIS \\
& & CO2_AIR_NLIS \\
L2 & $\mathrm{XCH}_{4}$ & CH4_SCI_WFMD \\
& & CH4_SCI_IMAP \\
& & CH4_GOS_OCFP \\
& & CH4_GOS_SRFP \\
& & CH4_GOS_OCPR \\
L2 & & CH4_GOS_SRPR \\
& $\mathrm{Mid}-t r o p o s p h e r i c$ & CH4_IASA_NLIS \\
Merged L2 & $\mathrm{CH}_{4}$ & CH4_IASB_NLIS \\
Merged L2 & $\mathrm{XCH}_{2}$ & XCO2_EMMA \\
Merged L3 & $\mathrm{XCO}_{2}$ & XCH4_EMMA \\
Merged L3 & $\mathrm{XCH}_{4}$ & XCO2_OBS4MIPS \\
\hline
\end{tabular}

\subsection{Data Quality}

The data quality of the $\mathrm{XCO}_{2}$ and $\mathrm{XCH}_{4}$ data products has been estimated by comparisons with the corresponding ground-based data products of the Total Carbon Column Observing Network (TCCON) [12]. The overall L2 products comparison results are shown in Fig. 3 for the $\mathrm{XCO}_{2}$ and in Fig. 4 for $\mathrm{XCH}_{4}$. As can be seen, the single footprint random error is about $2 \mathrm{ppm}$ for $\mathrm{XCO}_{2}$ and $50-90 \mathrm{ppb}$ for SCIAMACHY $\mathrm{XCH}_{4}$ and around $20 \mathrm{ppb}$ for GOSAT $\mathrm{XCH}_{4}$. The relative accuracy is around $0.5 \mathrm{ppm}$ for $\mathrm{XCO}_{2}$ and around $10 \mathrm{ppb}$ for SCIAMACHY $\mathrm{XCH}_{4}$ and around $5 \mathrm{ppb}$ for GOSAT $\mathrm{XCH}_{4}$. Stability in terms of linear bias drift is high for all products.

The IASI and AIRS mid-tropospheric products have been compared with aircraft observations [8] and it has been estimated that the single footprint random errors are around $1 \mathrm{ppm}$ for IASI $\mathrm{CO}_{2}$, around $1.3 \mathrm{ppb}$ for AIRS $\mathrm{CO}_{2}$ and $12 \mathrm{ppb}$ for $\mathrm{CH}_{4}$. Relative accuracy is approx. $0.5 \mathrm{ppm}$ for IASI $\mathrm{CO}_{2}$ and around $5 \mathrm{ppb}$ for IASI $\mathrm{CH}_{4}$.

\section{Summary and Conclusions}

An overview about a new data set of satellite-derived $\mathrm{CO}_{2}$ and $\mathrm{CH}_{4}$ data products relevant for carbon and climate related research has been presented.

The data products have been generated in the framework of the Copernicus Climate Change Service (C3S) and they are publicly and free-of-charge available for interested users 


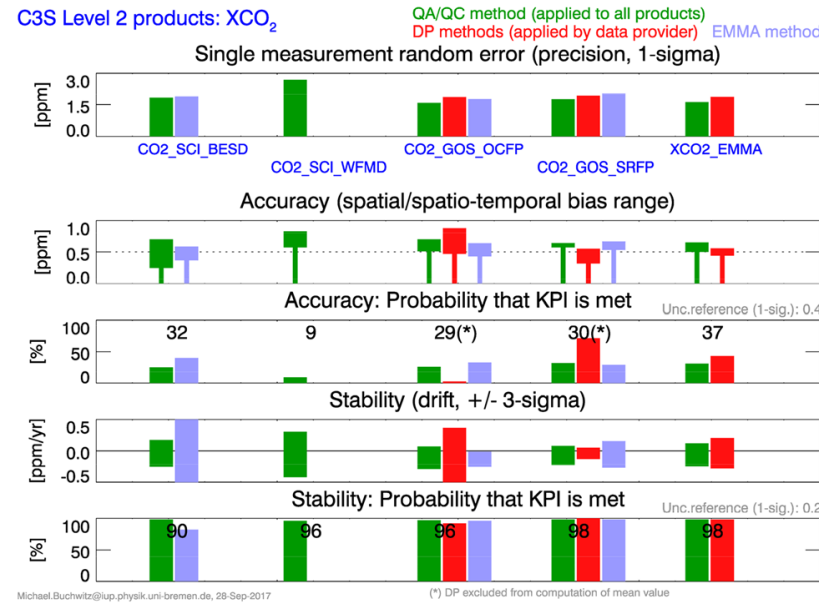

Fig. 3 Data quality overview $\mathrm{XCO}_{2} \mathrm{~L} 2$ products. From top to bottom: random error, relative accuracy, probability that relative accuracy is $<0.5 \mathrm{ppm}$, stability, probability that stability is $<0.5 \mathrm{ppm} / \mathrm{year}$. From [8]

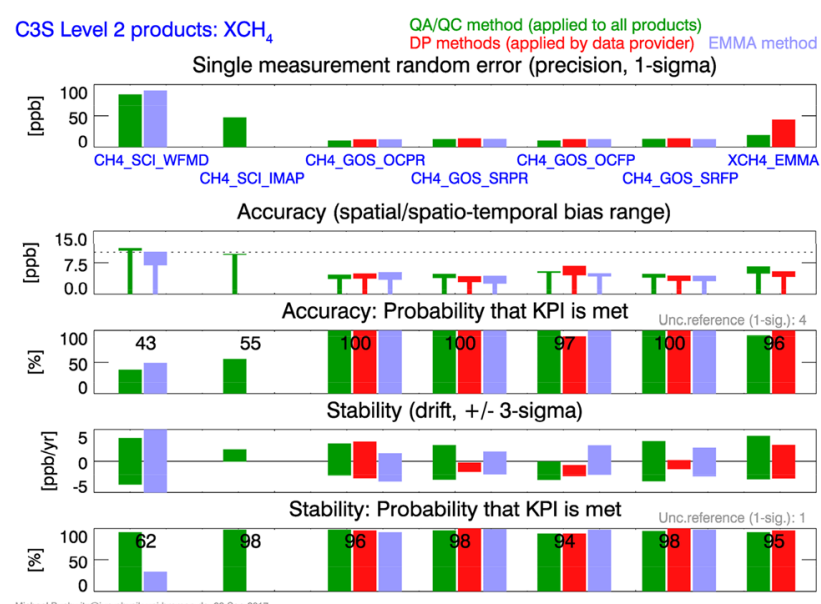

Fig. 4 Data quality overview $\mathrm{XCH}_{4} \mathrm{~L} 2$ products. From top to bottom: random error, relative accuracy, probability that relative accuracy is $<10 \mathrm{ppb}$, stability, probability that stability is $<3 \mathrm{ppb} / \mathrm{year}$. From [8]

including documentation via the Copernicus Climate Data Store (CDS) accessible via the C3S website [3].

Currently, the data set covers the time period 2003-2016, but it is planned to extend it each year by year one additional year. The next data set will cover the time period 2003-2017 and will be available end of 2018 .

Acknowledgements This study has been funded in parts by the European Space Agency (ESA) (via the GHG-CCI project of ESA's Climate Change Initiative (CCI, http://www.esa-ghg-cci.org/)), by the Copernicus Climate Change Service (C3S) implemented by the European Centre for Medium-Range Weather Forecasts (ECMWF) on behalf of the European Commission (https://climate.copernicus.eu/) and by the State and the University of Bremen. The University of Leicester GOSAT retrievals used the ALICE High Performance Computing Facility at the University of Leicester. We thank ESA/DLR for providing us with SCIAMACHY Level 1 data products and JAXA for GOSAT Level 1B data. We also thank ESA for making these GOSAT products available via the ESA Third Party Mission archive. We thank NIES for the operational GOSAT $\mathrm{XCO}_{2}$ Level 2 product and the NASA/ACOS team for the GOSAT ACOS Level $2 \mathrm{XCO}_{2}$ product. We also thank the TCCON team for making available the ground-based TCCON retrievals used for validation of the satellite data products (http://www.tccon.caltech.e $\mathrm{du} /)$.

Open Access This article is distributed under the terms of the Creative Commons Attribution 4.0 International License (http://creativecomm ons.org/licenses/by/4.0/), which permits unrestricted use, distribution, and reproduction in any medium, provided you give appropriate credit to the original author(s) and the source, provide a link to the Creative Commons license, and indicate if changes were made.

\section{References}

1. IPCC (2013) Climate change 2013: the physical science basis, Working Group I contribution to the fifth assessment report of the intergovernmental report on climate change. Cambridge University Press, Cambridge

2. Buchwitz M, Reuter M, Schneising O et al (2017) Global satellite observations of column-averaged carbon dioxide and methane: the GHG-CCI XCO $\mathrm{X}_{2}$ and $\mathrm{XCH}_{4}$ CRDP3 data set. Remote Sens Environ 203:276-295

3. C3S website (https://climate.copernicus.eu/) including Climate Data Store (CDS, https://cds.climate.copernicus.eu)

4. Le Quéré C, Andrew RM, Friedlingstein P et al (2018) Global carbon budget 2017. Earth Syst Sci Data 10:405-448. https://doi. org/10.5194/essd-10-405-2018

5. Houweling S, Krol M, Bergamaschi P et al (2014) A multi-year methane inversion using SCIAMACHY, accounting for systematic errors using TCCON measurements. Atmos Chem Phys 14:3991-4012

6. Worden JR, Bloom AA, Pandey S et al (2017) Reduced biomass burning emissions reconcile conflicting estimates of the post-2006 atmospheric methane budget. Nat Commun. https://doi.org/10.10 38/s41467-017-02246-0

7. Buchwitz M, Reuter M, Schneising-Weigel O et al (2017) Product user guide and specification (PUGS) - main document. Technical report Copernicus Climate Change Service (C3S). C3S website https://climate.copernicus.eu/. 20 Oct 2017, p 91

8. Buchwitz M, Reuter M, Schneising-Weigel O et al (2017) Product quality assessment report (PQAR) - main document. Technical report Copernicus Climate Change Service (C3S), available from C3S website https://climate.copernicus.eu/. 20 Oct 2017, p 103

9. Global Climate Observing System (GCOS) (2016) The global observing system for climate: implementation needs. World Meteorological Organization (WMO), GCOS-200 (GOOS-214), Geneva, p 325

10. GHG-CCI website. http://www.esa-ghg-cci.org/

11. Reuter M, Boesch H, Bovensmann $\mathrm{H}$ et al (2013) A joint effort to deliver satellite retrieved atmospheric $\mathrm{CO}_{2}$ concentrations for surface flux inversions: the ensemble median algorithm EMMA. Atmos Chem Phys 13:1771-1780

12. Wunch D, Toon GC, Blavier J-FL et al (2011) The total carbon column observing network. Philos Trans R Soc A 369:2087-2112 